\title{
Studies on Exploration of Psyllium Husk as Prebiotic for the Preparation of Traditional Fermented Food "Buttermilk"
}

\author{
K. Deepika Shree ${ }^{1 *}$, H.W. Deshpande ${ }^{1}$ and M.A. Bhate ${ }^{2}$ \\ ${ }^{1}$ Department of Food and Industrial Microbiology, Department of Food Science and \\ Technology, College of Food Technology, Vasantrao Naik Marathwada Vidyapeeth, \\ Parbhani -431402(Maharashtra) India \\ ${ }^{2}$ Department of Microbiology, Shivaji College, Parbhani - 431402 (Maharashtra) India \\ *Corresponding author
}

A B S T R A C T

\begin{tabular}{|c|c|}
\hline Keywords & \\
\hline $\begin{array}{l}\text { Psyllium husk, } \\
\text { Prebiotic, } \\
\text { Biochemical tests, } \\
\text { Lactic acid } \\
\text { bacteria. }\end{array}$ & \multirow{3}{*}{$\begin{array}{l}\text { In the following study two LAB cultures were isolated from curd and } \\
\text { pickle. The various morphological and biochemical tests were performed. } \\
\text { The proximate analysis of Psyllium husk was done followed by assessing } \\
\text { of psyllium husk as prebiotics. Psyllium husk was incorporated into } \\
\text { Buttermilk and studied the effect of psyllium in the prepared dairy product. } \\
\text { Several papers were reviewed to find out psyllium husk role in the } \\
\text { prevention and treatment of chronic diseases. }\end{array}$} \\
\hline Article Info & \\
\hline $\begin{array}{l}\text { Accepted: } \\
\text { 29 June } 2017\end{array}$ & \\
\hline $\begin{array}{l}\text { Available Online: } \\
10 \text { July } 2017\end{array}$ & \\
\hline
\end{tabular}

\section{Introduction}

Isabgol (Psylliums), the common name in India for $P$. ovata, comes from the Persian words "isap" and "ghol" that mean horse ear, which is descriptive of the shape of the seed.India is largest exporter of isabgol in the world; it has been introduced and cultivated in North Gujarat and adjoining parts of Western Rajasthan and Madhya Pradesh. However, the crop is spreading in nontraditional parts of the country such as Punjab, Haryana, Uttar Pradesh and Karnataka (Jat et al., 2015).The husk is about $10-25 \%$ of seed on dry weight basis. The husk obtained after milling is white hydrophilic material forming clear and colorless mucilaginous gel after water absorption. Psyllium seed husk is composed of mucilaginous polysaccharides, with a highly branched acidic arabinoxylan containing a xylan backbone (Washington et al., 1998 and Blumenthal et al., 2000).

Prebiotics are mainly carbohydrates by nature. According to $\mathrm{FAO} / \mathrm{WHO}$ the definition of prebiotics is "non digestible substances that provide a beneficial physiological effect on the host by selectively stimulating the favourable growth or activity of a limited number of indigenous bacteria". Next to inulin and fructo-oligosaccharides, 
the two most intensively studied prebiotics are arabinoxylan-oligosaccharides (AXOS) and are being considered as a potential new class of prebiotic components.

Consumption of fermented dairy products has been an essential part of dietary habits since ancient times because of their immense nutritional and therapeutic virtues.Process of fermentation also assists in development of flavour, texture and other organoleptic characteristics unique to it. About 9 percent of milk produced in India is used for the manufacture of fermented dairy products (Singh, 2005) dominated by dahi,flavoured acidic products characterised by buttery flavour and produced by using mesophilic starters (Sarkar, 2008).

Buttermilk is produced when fermented milk or cream is churned into butter, it is produced as a by-product. It contains water-soluble components including lactose, milk salts and vitamins as well as milk proteins and residual fat.Traditional buttermilk is the liquid left after butter making from fermented cream or milk, which has been fermented by naturally occurring lactic acid bacteria (LAB) (Libudzisz and Stepaniak, 2003; Sodini et al., 2006). The keeping quality of good buttermilk at $5^{\circ} \mathrm{C}$ is approximately 2 weeks. In India the standards for contamination prescribe that coli form count should be less than 10 per $\mathrm{ml}$ and yeast \& mold count should be less than 100 per $\mathrm{ml}$.

Probiotics can be used as single or mixed cultures. The following properties and functions have been attributed to probiotics: they adhere to host epithelial tissue; they are acid resistant and bile tolerant; they are safe, non-pathogenic and non-carcinogenic; they cause improvement of the intestinal microflora; they have a cholesterol lowering, immune stimulating and allergy lowering effect; synthesize and enhance the bioavailability of nutrients (Ouwehand et al.,
2002; Saito, 2004; Grajek et al., 2005). Additionally, probiotics produce a variety of beneficial compounds such as antimicrobials, lactic acid, hydrogen peroxide, and a variety of bacteriocins (Holzapfel et al., 2001; Gorbach, 2002).

Probiotics should have the ability to interact with the host microflora and competitive with microbial pathogens, bacterial, viral, and fungal (Gorbach, 2002). Thus, when prebiotic and probiotic works coherently, a synergistic relationship is developed between them and together they are termed as "synbiotics". .

Lactic acid bacteria are the most well known and widely used probiotic bacteria. The lactic acid bacteria are gram-positive, usually nonmotile, non-sporulating, catalase negative, cocci or rods. They produce lactic acid as a sole product of fermentative metabolism of carbohydrate substrates. Most lactobacillus species are homofermentaive, producing mainly lactic acid as metabolic byproduct but some are heterofermentative i.e., they produce ethanol, $\mathrm{CO} 2$ as well as lactate respectively. Thus, to fulfill the nutritional requirement of probiotic bacteria, prebiotics plays a major role.

\section{Materials and Methods}

\section{Material}

Psyllium husk, spices like Cumin, Ajowan Caraway seeds and Corriander leaves were procured from the local market of Parbhani. The spices were ground in a laboratory grinder for mixing with Buttermilk.

\section{Methods}

\section{Isolation and Identification of lactic acid bacteria}

Curd and pickle samples were used for isolation of probiotic LAB cultures. From 
each sample, 1: 10 serial dilution was subsequently made using sterile normal saline $(0.85 \%)$ followed by making a 10 fold serial dilution. Then $0.1 \mathrm{ml}$ from each dilution was subcultured asceptically on MRS agar using pour plate technique. All the plates were then incubated at $37^{0} \mathrm{c}$ for $24-48$ hours. Isolated colonies were selected and inoculated into MRS broth and incubated for 24 hours.

\section{Identification of probiotic cultures}

The pure isolated colony formed on MRS agar plates was identified using gram staining, biochemical tests and carbohydrate fermentation profile (FSSAI, 2012). The identification was performed according to Bergey's Manual of Determinative Bacteriology. The various tests performed are as followed

\section{Gram staining}

The heat fixed smear of bacterial culture was stained with primary stain crystal violet, and then fixed by the mordant i.e. Gram's Iodine. It was decolorized by alcohol and then counterstained with safranin. The bacteria as were observed under compound microscopes with a magnification of $45 \mathrm{x}$ and $100 \mathrm{x}$.

\section{Motility test}

The 'Hanging drop' technique used to observe motility in bacteria. A loopfull of bacterial suspension was hung from the center of a cover slip into the cavity of a cavity slide. The edge of the drop was focused under a microscope using oil immersion objective.

\section{Biochemical tests}

\section{Catalase test}

A small quantity of culture from a single, isolated colony was taken using a sterile loop and deposited at the centre of a clean microscope slide. The slide was flooded with $3-5 \%$ hydrogen peroxide solution. Bubble or effervescence formation is indicative of a positive reaction.

\section{Citrate test}

A tube of Koser citrate medium was inoculated with culture and incubated at $35^{\circ} \mathrm{C}$ for $96 \mathrm{hrs}$. The inoculated media was observed for turbidity due to growth.

\section{Indole test}

An isolate is inoculated into a $5 \mathrm{ml}$ tryptone broth and incubated for $24 \mathrm{hrs}$. Add $0.2-0.3 \mathrm{ml}$ of Kovac's reagent to the $24 \mathrm{hr}$ culture and the culture is left to stand. The yellow reagent partitions from the medium and settles onto the surface of the tryptone water. Development of a deep red color in this surface layer indicates a positive reaction.

\section{Hydrogen sulphide test}

A tube of TSI agar was inoculated by stabbing the butt and streaking the slope. It was then incubated for 24-48hrs and observed for blackening due to $\mathrm{H}_{2} \mathrm{~S}$ production.

\section{Methyl red reaction}

The methyl red indicator was dissolved in $300 \mathrm{ml}$ of alcohol, and made up to $500 \mathrm{ml}$ with distilled water. Test cultures were incubated and grown in MR-VP broth for $48 \mathrm{hrs}$ at $37^{\circ} \mathrm{C}$. Then 5 or 6 drops of reagents were to cultures and observed for color changes. A red color is interpreted as MR positive and yellow color as MR negative.

\section{Urease test}

The urea media was inoculated heavily with the culture being tested and incubated for $24 \mathrm{hrs}$ at $35^{\circ} \mathrm{C}$. If urease is present, the urea 
split to form ammonia, which changes the color of the indicator from yellow to pink.

\section{Carbohydrate fermentation}

Carbohydrate fermentation test detects the ability of microorganisms to ferment a specific sugar. One tube of each carbohydrate media (containing specific sugar) was inoculated with culture and incubated at $35^{\circ} \mathrm{C}$ for $24 \mathrm{hrs}$.

Acid production is indicated by a change in color and gas production can be detected by observation of gas collection in the inverted Durham tube.

\section{Molecular identification of probiotic cultures}

The isolated bacteria were sent to Agharkar Research Institute, Pune, where strains of promising probiotic LAB were identified by 16S rRNA multiplex PCR analysis (Markiewicz and Biedrycka, 2005; Janda and Abbott, 2007). This was in confirmation to the morphological and biochemical tests performed atDepartment of Food and Industrial Microbiology, College of Food Technology, V.N.M.K.V., Parbhani.

\section{Preparation of MRS medium}

All the ingredient will be suspended in distilled water and heated to dissolve the medium completely. The medium will be then sterilized in autoclave at $15 \mathrm{lbs}$ pressure for 15 minutes

\section{Preparation of starter culture}

The probiotic organisms will be individually grown in MRS broth at $37^{\circ} \mathrm{C}$ for $24 \mathrm{hr}$ using $1 \%$ inoculum. The cultivated MRS broth will then be centrifuged at 4,000 rpm for $10 \mathrm{~min}$. The biomass will be taken as starter culture.
To carry out proximate analysis of psyllium husk

\section{Moisture}

The moisture content of ground Psyllium Husk was determined according to method No. 44-15 of (A.A.C.C., 2000).

\section{Crude fat}

The method employed was that of solvent extraction using a Soxhlet extraction as described in method No. 30-10 (A.A.C.C., 2000).

\section{Crude protein}

The crude protein was determined by the Kjeldhal ${ }^{\text {ee }} \mathrm{s}$ method as described in method No. 46-10 of (A.A.C.C., 2000).

\section{Crude fiber}

Crude fiber content was determined by following the method No. 32-10 as described in (A.A.C.C., 2000).

\section{Ash}

The ash content was determined as a total inorganic matter by incineration of the samples at $600^{\circ} \mathrm{C}$ according to method No. 08-01 of (A.A.C.C., 2000).

\section{Total carbohydrate}

Carbohydrates were calculated by difference method as follows.

Carbohydrates $=100-\%$ (Moisture + Fat + Protein + Ash + Crude Fiber)

\section{Physico-chemical analysis of Curd}

\section{Acidity}

The acidity of curd sample was calculated by standard A.O.A.C.method (2000). 
pH

The $\mathrm{pH}$ of curd was determined by using a Digital $\mathrm{pH}$ meter.The $\mathrm{pH}$ meter was standardized using $\mathrm{pH} 4.0$ and $\mathrm{pH} 9.0$ buffer solutions. The $10 \mathrm{ml}$ of curd was stirred before $\mathrm{pH}$ measurement. And temperature of sample was maintained at $20^{\circ} \mathrm{C}$.

\section{Total solids}

Total solid content of curd was determined by using gravimetric method as per the procedure described in IS: 12333, 1997; ISO: 6731, 1989.

\section{Preparation of probiotic buttermilk}

Above prepared starter culture $(2 \mathrm{~mL})$ was then added to the pasteurized milk $(100 \mathrm{~mL})$ to obtain 2 percent inoculation. It was allowed to ferment in incubator at $37^{0} \mathrm{C}$ for $8 \mathrm{~h}$. After incubation, the drink was kept at refrigeration temperature for future use.

\section{Sensory evaluation}

The sensory characteristics of psyllium husk added Buttermilk will be evaluated at weekly intervals using 9 point Hedonic scale test by a panel of ten semi trained members.

Sensory parameters of psyllium added Buttermilk color, body, flavor, Overall Acceptability.

\section{Statistical analysis}

The experimental data were analyzed using analysis of variance (ANOVA) followed by Duncan's multiple range tests $(\mathrm{P}<0.05)$ to determine a significant difference among samples.

The data were analyzed according to user's guide of statistical analysis system (SAS, 1996).

\section{Microbial analysis of prepared probiotic Buttermilk}

The viable count of mixed culture was determined by the Total plate count method using Man - Rogosa-Sharpe agar (MRS agar) and the results were expressed as $\mathrm{CFU} / \mathrm{ml}$. The yeast and mold count of buttermilk was determined using potato dextrose agar medium. The coli-form and basically $E$. coli are the indicator microbes of water contamination by feces. The coliform gives red color colonies on the MacConkey agar (Chris et al., 2006).

\section{Results and Discussion}

\section{Isolation and identification of probiotic LAB cultures}

Lactic acid bacteria (LAB) are industrially important food grade bacteria and known for their fermentative, nutritional, and health benefits (Badr et al., 2005). Pure isolated colonies from curd and pickle were primarily subjected to various morphological and biochemical tests. These primary tests were carried out in the following standard protocols at Department of Food Technology, CFT, V.N.M.K.V, Parbhani. The results are presented in table 1 . The results in table 1 showed that the isolates were lactobacilli strains as both the isolates were rod shaped, non-motile, showed no catalase activity, $\mathrm{H}_{2}$ Snegative, Indole negative and utilized glucose, fructose and lactose (Bergey's Manual of Determinative Bacteriology).An important characteristic used in the differentiation of LAB cultures is the mode of glucose fermentation under standard conditions. Carbohydrate fermentation profile shows that the isolate from curd fermented only glucose, fructose and lactose and there was no gas production during glucose fermentation suggesting that the isolate is a homo fermentive LAB species, Whereas the 
isolate from pickle fermented all the 5 sugars in the test and gas production in the form of bubble production from glucose fermentation was also noticed in the Durham tube because of which we can conclude the isolate is facultative hetero fermentive. Further confirmation of identification results by $16 \mathrm{~S}$ rRNA multiplex PCR analysis of the isolated cultures at ARI, Pune revealed that the isolates obtained from curd and pickle were Lactobacillus bulgaricus and Lactobacillus acidophilus respectively. Probiotic activity of the culture can be ascribed to its ability to produce substances with antimicrobial properties. Lactobacilli are known to inhibit the growth of pathogenic bacteria, possibly by producing inhibitory compounds such as organic acids, hydrogen peroxide and bacteriocins (Jacobsen et al., 1999).

\section{Physico-chemical characteristics of curd}

The physicochemical characteristics of curd were found to contain Acidity $(0.610 \%), \mathrm{pH}$ (4.68) and TSS ( $12^{\circ}$ Brix) as depicted in table 2 . The results were in close agreement to the results obtained by Aneja (1997). It is generally considered that high acidity favours the formation of a firm curd, but Webb et al., (1974) demonstrated that curd firmness increased with decreasing $\mathrm{pH}$ to a maximum at pH 5.8 below which it decreased rapidly. Curd with high fat content may be prepared from buffalo milk and that of low fat from skimmed milk, the contribution of milk fat to the flavour of milk. The body is expected to be soft and firm, free from gas holes (Aneja, 1997).

\section{Psyllium husk}

\section{Proximate analysis of Psyllium husk}

The physicochemical characteristics of Psyllium Husk were found to contain Moisture content (7.20\%), Fat (1.84\%), Protein(2.93\%),
Crude fibre (3.14\%), Carbohydrate $(85.29 \%)$ and Ash (2.53\%) as depicted in table 3. The results were in close agreement to the results obtained by Liangh et al., (2003) and Guo et al., (2008).

\section{To assess the use of Psyllium husk and LAB culture as synbiotics}

Fermentable fibers may provide a number of health benefits by altering the composition of the intestinal flora studied by Joanne Slavin, (2013).

In order to assess the use of Psyllium husk and LAB as synbiotics the curd prepared by using Lactobacillus acidophilus and Lactobacillus bulgaricus having different concentrations of Psyllium husk was serial diluted and out of which $10^{6}$ to $10^{8}$ dilution aliquots are plated on MRS growth media and incubated for $48 \mathrm{hrs}$ at $37^{\circ} \mathrm{C}$. From the observations it is noted that as the concentration of Psyllium increases the microbial count was increased. The results are presented in table 4 . The graphical representation of the table is presented in figure 1.

Where.

Control = LAB culture is grown on MRS media without Psyllium, $\mathrm{A}=$ Addition of $0.2 \mathrm{~g}$ Psyllium husk and LAB culture on MRS media, $\mathrm{B}=$ Addition of $0.3 \mathrm{~g}$ Psyllium husk and LAB culture on MRS media, $\mathrm{C}=$ Addition of $0.4 \mathrm{~g}$ Psyllium husk and LAB culture on MRS media

The references quoted in context supports that the assessing of Psyllium and LAB as synbiotic is in support of insisting the prebiotic property of psyllium which when provided for the growth of cultures provides the favourable growth condition for proficient growth of beneficial microorganisms. 
Effect of Psyllium husk on physicochemical characteristics of Probiotic Buttermilk

The data with respect to assessing the use of Psyllium husk in Buttermilk were presented in table 5. The Psyllium added Buttermilk contained the TSS ( $\left.15^{\circ} \mathrm{Brix}\right), \mathrm{pH}$ (4.82), Acidity $(0.613 \%)$, Moisture $(89.95 \%)$, Fat $(0.50 \%)$, Protein $(3.76 \%)$, Carbohydrates $(5.41 \%)$ and Ash $(0.38 \%)$. The results are found to be close in agreement with the study conducted by Sonalika Srivastava et al., (2015). The graphical representation of the table 5 is presented in figure 2 .

The moisture is noted to be in decreasing order with increasing the addition of Psyllium husk from 90.16 in control to 89.95 in sample C.Fat content of Psyllium added Buttermilk is reduced compared to that of control sample without the addition of Psyllium.Ash content increased significantly due to fermentation process.It was observed that the carbohydrate content of prepared probiotic buttermilk was 5.41 percent in sample $\mathrm{C}$.

Where,

Control= Probiotic Buttermilk prepared from 0 percent addition of Psyllium Husk, A = Probiotic Buttermilk prepared from 0.2 percent addition of Psyllium Husk, B = Probiotic Buttermilk prepared from 0.3 percent addition of Psyllium Husk, C $=$ Probiotic Buttermilk prepared from 0.4 percent addition of Psyllium Husk. And all samples were inoculated with 1 percent each equal proportion of Lactobacillus acidophilus and Lactobacillus bulgaricus.

\section{Sensory evaluation of buttermilk}

The sensorial quality characteristics of Probiotic Buttermilk play a vital role in attracting consumers to purchase the product. Consumer judges probiotic Buttermilk quality on the basis of its sensory parameters such as color, flavor, taste, texture etc. Sensorial evaluation was done using 9 point Hedonic scale. The Probiotic Buttermilk was evaluated for acceptability based on characteristics such as color, flavor, taste and texture. The sensorial characteristics of Probiotic Buttermilk are summarized in table 6. The results are graphically represented in figure 3 .

Where, probiotic Buttermilk inoculated with 1 percent eachequal proportion of Lactobacillus acidophilus and Lactobacillus bulgaricus but variation only in addition of Psyllium Husk i.e., Control= probiotic Buttermilk prepared from 0 percent addition of Psyllium husk, $\mathrm{A}=$ Probiotic Buttermilk prepared from 0.25 percent addition of Psyllium Husk, B = Probiotic Buttermilk prepared from 0.3 percent addition of Psyllium Husk, C $=$ Probiotic Buttermilk prepared from 0.4 percent addition of Psyllium Husk.

\section{Colour}

Color serves as a preliminary parameter for the acceptance of food and indicates the fitness of Probiotic Buttermilk for consumption. The results presented in table 6 showed that the color of Probiotic Buttermilk was comparably same in concentration of starter culture but variation only in addition of Psyllium husk and acceptable color was observed in sample $\mathrm{C}$ and containing 0.4 percent Psyllium Husk and 1 percent each equal proportion of Lactobacillus acidophilus and Lactobacillus bulgaricus. The maximum score for color of probiotic Buttermilk was obtained by sample $\mathrm{C}$ followed by control.

\section{Flavour}

Fermentation makes the drinks palatable by enhancing its aroma and flavor. These organoleptic properties make fermented drinks more popular than the unfermented one in terms of consumer acceptance (Chelule 
et al., 2010).The score for flavor of Probiotic Buttermilk ranged from 7.3-7.7 among the Probiotic Buttermilk samples prepared from different level of Psyllium Husk addition. The Probiotic Buttermilk sample C scored significantly higher score in comparison with other samples where control had the higher score. However the sample B scored lower for the flavor.

\section{Mouthfeel}

Mouthfeel in the health food is usually affected by characteristics changes during manufacture. The maximum score for taste was in the sample $C$ followed by control and A.While the sample B scored the lower value. The taste was found to increase with increase in addition of Psyllium husk. Verbeke, (2006) reported taste to be the major force in food acceptance, which, according to Tepper and Trail, (1998) supersedes health in driving consumers' food choice.

\section{Body}

Texture (consistency) is a group of physical characteristics, sensed by mouth feel. Textural properties of all samples were found to be increase with addition of starter culture and Psyllium Husk. The buttermilk samples added with starter culture and Psyllium husk are more viscous than control. Maximum textural score (i.e. 8.2) was secured by sample C, followed by sample B (i.e. 7.7), while the minimum score (i.e. 7.2) was observed in $\mathrm{A}$ sample.

Table.1 Morphological and biochemical tests of unknown isolates

\begin{tabular}{|c|c|c|c|}
\hline Sl.No. & Test & Culture from Curd & Culture from Pickle \\
\hline 1 & Gram Staining & $+\mathrm{ve}$ & $+\mathrm{ve}$ \\
\hline 2 & Shape & Rod & Rod \\
\hline 3 & Motility & Non Motile & Non Motile \\
\hline 4 & Catalase & -ve & -ve \\
\hline 5 & $\mathrm{H}_{2} \mathrm{~S}$ & -ve & -ve \\
\hline 6 & Methyl Red Reaction & $+\mathrm{ve}$ & +ve \\
\hline 7 & Urease & -ve & -ve \\
\hline 8 & \multicolumn{3}{|l|}{ Carbohydrate Fermentation } \\
\hline & Glucose & $+\mathrm{ve}$ & +ve \\
\hline & Glucose (Gas production) & -ve & $+\mathrm{ve}$ \\
\hline & Fructose & $+\mathrm{ve}$ & +ve \\
\hline & Sucrose & -ve & $+\mathrm{ve}$ \\
\hline & Lactose & $+\mathrm{ve}$ & $+\mathrm{V}$ \\
\hline & Mannose & -ve & $+\mathrm{ve}$ \\
\hline 9 & Citrate & -ve & -ve \\
\hline 10 & Indole Production Test & -ve & $-\mathrm{ve}$ \\
\hline
\end{tabular}


Table.2 Physico-chemical characteristics of curd

\begin{tabular}{|l|c|c|}
\hline Sr.no & Physical Parameters & Curd \\
\hline 1. & Acidity & 0.610 \\
\hline 2. & $\mathrm{pH}$ & 4.68 \\
\hline 3. & TSS & 12 \\
\hline
\end{tabular}

Table.3 Proximate analysis of Psyllium husk

\begin{tabular}{|c|c|}
\hline Parameters & Psyllium Husk \\
\hline Chemical & \\
\hline Moisture (\%) & 7.20 \\
\hline Fat (\%) & 1.84 \\
\hline Protein (\%) & 2.93 \\
\hline Crude Fiber (\%) & 3.14 \\
\hline Carbohydrates(\%) & 85.29 \\
\hline Ash (\%) & 2.53 \\
\hline
\end{tabular}

*Each value represents the average of three determinations

Table.4 To assess the use of Psyllium husk and LAB culture as synbiotics

$$
\text { Where. }
$$

Microbial count observed under different dilution and Incubation Periods in MRS growth media

Control $=\mathrm{LAB}$ culture is grown on MRS media without Psyllium, $\mathrm{A}=$ Addition of $0.2 \mathrm{~g}$ Psyllium husk and LAB culture on MRS media, $\mathrm{B}=$ Addition of 0.3g Psyllium husk and LAB culture on MRS media, $\mathrm{C}=$ Addition of 0.4g Psyllium husk and LAB culture on MRS media

Table.5 Effect of Psyllium husk on physico-chemical characteristics of Probiotic Buttermilk

\begin{tabular}{|c|c|c|c|c|c|c|c|c|}
\hline \multirow{2}{*}{ Samples } & \multicolumn{3}{|c|}{ Physical parameters } & \multicolumn{5}{c|}{ Chemical parameters } \\
\cline { 2 - 9 } & $\begin{array}{c}\text { T.S.S } \\
\left({ }^{\circ} \text { Brix }\right)\end{array}$ & $\mathbf{p H}$ & $\begin{array}{c}\text { Acidity } \\
(\boldsymbol{\%})\end{array}$ & $\begin{array}{c}\text { Moisture } \\
(\boldsymbol{\%})\end{array}$ & $\begin{array}{c}\text { Fat } \\
(\boldsymbol{\%})\end{array}$ & $\begin{array}{c}\text { Protein } \\
(\boldsymbol{\%})\end{array}$ & $\begin{array}{c}\text { Carbohydrate } \\
(\boldsymbol{\%})\end{array}$ & $\begin{array}{c}\text { Ash } \\
(\boldsymbol{\%})\end{array}$ \\
\hline Control & 10 & 4.80 & 0.610 & 90.16 & 0.69 & 3.80 & 5.03 & 0.32 \\
\hline $\mathrm{A}$ & 11 & 4.81 & 0.610 & 90.00 & 0.65 & 3.79 & 5.22 & 0.34 \\
\hline $\mathrm{B}$ & 13 & 5.97 & 0.611 & 89.98 & 0.60 & 3.78 & 5.28 & 0.36 \\
\hline $\mathrm{C}$ & $\mathbf{1 5}$ & $\mathbf{4 . 8 2}$ & $\mathbf{0 . 6 1 3}$ & $\mathbf{8 9 . 9 5}$ & $\mathbf{0 . 5 0}$ & $\mathbf{3 . 7 6}$ & $\mathbf{5 . 4 1}$ & $\mathbf{0 . 3 8}$ \\
\hline $\mathrm{SE}+$ & 0.328 & 0.082 & 0.001 & 0.020 & 0.015 & 0.012 & 0.065 & 0.009 \\
\hline $\mathrm{CD}$ at 5\% & 1.086 & 0.025 & 0.003 & 0.061 & 0.049 & 0.035 & 0.216 & 0.030 \\
\hline
\end{tabular}

*Each value represents the average of three determinations

Where,

Control= Probiotic Buttermilk prepared from 0 percent addition of Psyllium Husk, A = Probiotic Buttermilk prepared from 0.2 percent addition of Psyllium Husk, B = Probiotic Buttermilk prepared from 0.3 percent addition of Psyllium Husk, C =Probiotic Buttermilk prepared from 0.4 percent addition of Psyllium Husk. 
Table.6 Sensory evaluation of probiotic Buttermilk

\begin{tabular}{|l|c|c|c|c|c|}
\hline Samples & Color & Flavor & Mouthfeel & Body & Overall Acceptability \\
\hline Control & 8.0 & 8.2 & 8.0 & 8.0 & 8.0 \\
\hline $\mathrm{A}$ & 7.9 & 7.3 & 7.2 & 7.2 & 7.4 \\
\hline $\mathrm{B}$ & 7.9 & 7.6 & 7.9 & 7.7 & 7.7 \\
\hline $\mathrm{C}$ & $\mathbf{8}$ & $\mathbf{7 . 7}$ & $\mathbf{8 . 5}$ & $\mathbf{8 . 2}$ & $\mathbf{8 . 1}$ \\
\hline $\mathrm{SE} \pm$ & 0.018 & 0.104 & 0.122 & 0.132 & 0.122 \\
\hline $\mathrm{CD}$ at 5\% & 0.054 & 0.345 & 0.406 & 0.438 & 0.406 \\
\hline
\end{tabular}

*Each value represents the average of five determinations

Where, probiotic Buttermilk inoculated with 1 percent eachequal proportion of Lactobacillus acidophilus and Lactobacillus bulgaricus but variation only in addition of Psyllium Husk i.e.,

Control= probiotic Buttermilk prepared from 0 percent addition of Psyllium husk, $\mathrm{A}=$ Probiotic Buttermilk prepared from 0.25 percent addition of Psyllium Husk,B = Probiotic Buttermilk prepared from 0.3 percent addition of Psyllium Husk,C =Probiotic Buttermilk prepared from 0.4 percent addition of Psyllium Husk.

Table.7 Viable counts (LAB) of probiotic Buttermilk during storage

\begin{tabular}{|c|c|c|c|}
\hline \multirow{2}{*}{ Time in (days) } & \multicolumn{3}{|c|}{ Viable count } \\
\cline { 2 - 4 } & $(\mathbf{c f u} / \mathbf{m l}) \mathbf{x 1 0}$ & $\left.\mathbf{( c f u}^{\mathbf{6}} / \mathbf{m l}\right) \mathbf{x 1 0}$ & $\left.\mathbf{( c f u}^{\mathbf{7}} \mathbf{m l}\right) \mathbf{x 1 0}$ \\
\hline $\mathbf{0}$ & 3.3 & 2.1 & 1.5 \\
\hline $\mathbf{2}$ & 4.1 & 2.6 & 1.9 \\
\hline $\mathbf{4}$ & 4.6 & 2.9 & 2.1 \\
\hline $\mathbf{6}$ & 4.9 & 3.0 & 2.1 \\
\hline
\end{tabular}

Table.8 Microbial analysis of Probiotic Buttermilk

\begin{tabular}{|l|c|c|c|}
\hline \multirow{2}{*}{$\begin{array}{l}\text { Storage period } \\
\text { day) }\end{array}$} & \multicolumn{3}{|c|}{ Microbial quality } \\
\cline { 2 - 4 } & $\begin{array}{l}\text { Total plate count } \\
\text { (cfu/ml)x10 }\end{array}$ & Yeast and mold (cfu/ml)x10 & $\begin{array}{c}\text { Coliform } \\
\text { count }\end{array}$ \\
\hline 0 & 2.9 & ND & ND \\
\hline 2 & 3.9 & 2.6 & ND \\
\hline 4 & 4.1 & 2.0 & ND \\
\hline 6 & 5.2 & 1.4 & ND \\
\hline
\end{tabular}

ND:Not detected

Fig.1 Assessing use of psyllium husk and LAB as synbiotics- probiotic Buttermilk

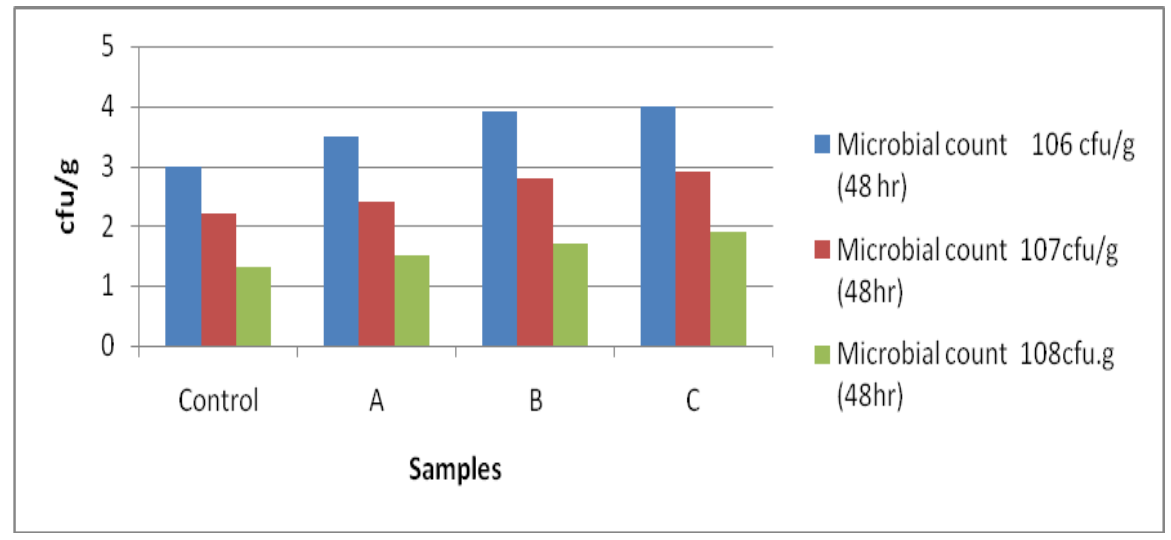


Fig.2 Effect of psyllium husk on physicochemical properties of probiotic Butter

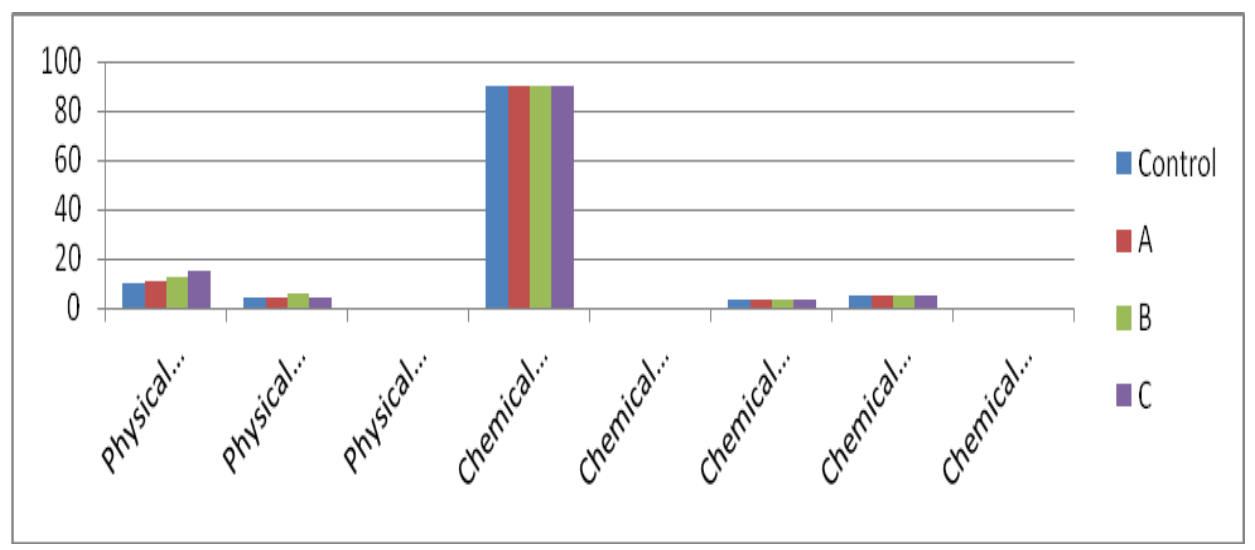

Fig.3 Sensory evaluation of probiotic Buttermilk

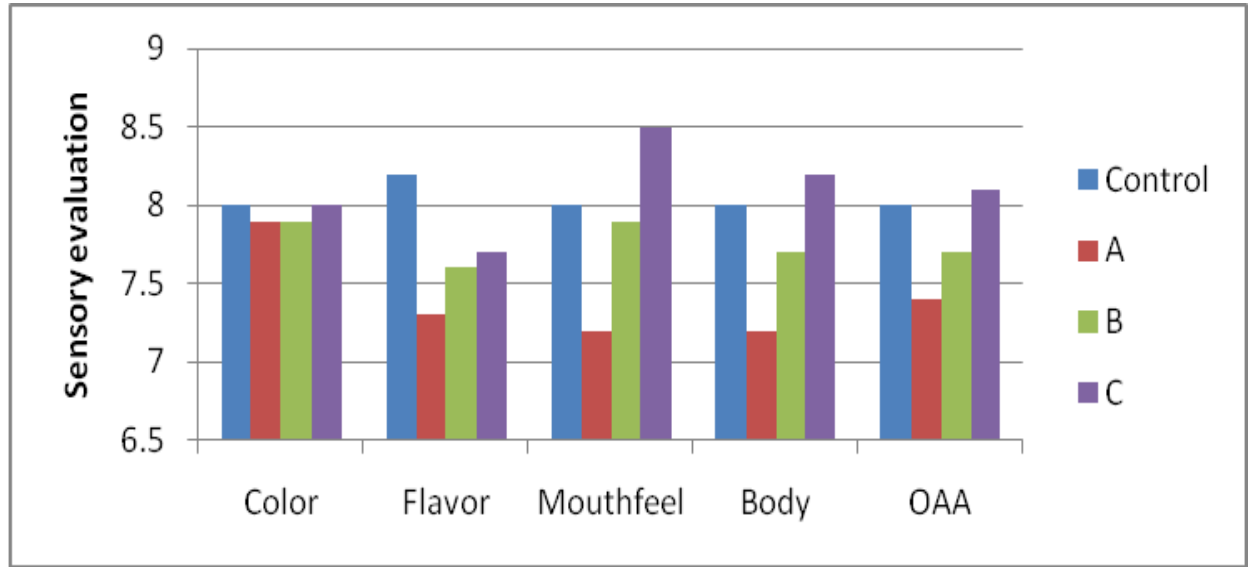

Fig.4 Viability count of probiotic Buttermilk.

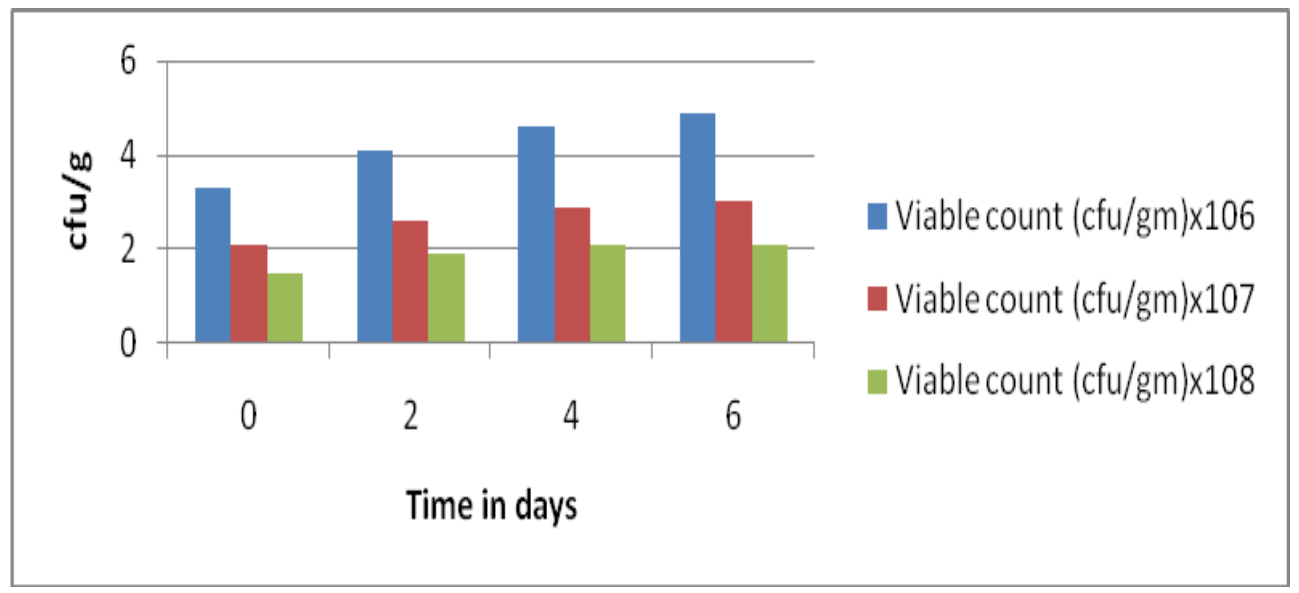

\section{Overall acceptability}

The maximum score for overall acceptability was observed in sample $\mathrm{C}$ inoculated with 1 percent each equal proportion of Lactobacillus acidophilus and Lactobacillus bulgaricus and 0.4 percent addition of Psyllium Husk, while the minimum score was 
observed in sample A and B. The control sample which is without addition of Psyllium husk has scored lower as compared to Sample $\mathrm{C}$ with 0.4 percent addition of Psyllium husk which means the sample $\mathrm{C}$ is nutritionally better as compared to control sample.

\section{Viable counts (LAB) present in probiotic Buttermilk during storage}

The total viable counts of Psyllium husk added accepted Buttermilk sample $\mathrm{C}$ was observed at different storage period on MRS agar media.The results are presented in table 7. It is evident that viable counts are observed at dilutions rate of $10^{6}, 10^{7}$ and $10^{8}$. The graphical representation of the below table is presented in figure 4.

A minimum range of $10^{6}-10^{7}$ plate microorganisms per gram or milliliter should be present in food product in order to meet the requirements of a probiotic food, as by the Japanese Fermented Milk and Lactic Acid Bacteria Drinks Association (Ishibashi and Shimanura, 1993).

\section{Microbial analysis of probiotic buttermilk}

The microbial analysis of probiotic buttermilk is tabulated in table 8. The accepted sample was subjected to microbial studies for total plate count, yeast and mold count and Coliform growth during the storage period as per method adopted by Cappuccino and Sherman (1996).

In conclusion, the Probiotic Buttermilk can be prepared by utilizing curd, ground spices, coriander leaves, salt and Psyllium husk using equal amount of 1 percent starter culture of LAB viz. L. acidophilus and L. bulgaricus. Acidity, $\mathrm{pH}$, viable probiotic count in probiotic Buttermilk samples are dependent on level of Psyllium addition. Good quality dairy probiotic buttermilk can be prepared by using $0.4 \mathrm{~g}$ of Psyllium with 2 percent starter culture and $8 \mathrm{hrs}$ fermentation period for curd having better overall sensory acceptability with storage for 6 days under refrigerated storage $\left(4^{\circ} \mathrm{C}\right)$. The process of preparation of probiotic Buttermilk can be techno economically feasible, justifies the suitability of incorporation of Psyllium husk in probiotic based health or functional food for commercial exploration.

\section{References}

A.O.A.C. 2000. Official methods of analysis, Association of Official Analytical Chemists. Washington DC

AACC. American Association of Cereal Chemists. 2000. Approved Methods of American Association of Cereal Chemists. The Am. Assoc. Cereal Chem.Inc., St. Paul. Minnesota.

Aneja, K.R. 1996. Experiments in microbilogy, plant pathology, tissue culuiture and mushroom cultivation. II Edition, 60-217pp

Badr, S., H.A.Karem, H. Hussein and D.ELHadedy. 2005. Characterization of nisin produced by Lactococcus lactis. Int. J. Agric. Biol., 7: 499-503

Blumenthal, M.A. Goldberg, J. Brinkman. 2000. Herbal Medicine: Expanded Commision E Monographs. Integrative Medicine Communications. Newton, MA.

Chelule, P.K., Mokoena, M.P. and Gqaleni, N. 2010. Advantages of traditional lactic acid bacteria fermentation of food in Africa. Curr. Res. Technol. Education Topics in Appl. Microbiol. Microbial Biotechnol., 1160-1167.

Deepak Mudgil, Sheweta Barak. 2016. Development of functional buttermilk by soluble fibre fortification. Agro Food Industry Hi Tech., 27(02): 44-47.

FSSAI. 2012. Lab Manual 14. Manual of methods of analysis of foods. p98-102 
Gorbach, S. 2002. Probiotics in the Third Millennium. Digest Liver Dis., 34(2): S2-S7.

Grajek, W., Olejnik, A. and Sip, A. 2005. Probiotics, prebiotics and antioxidants as functional foods. Acta Biochimica Polonica, 52(3): 665-671.

Guo, Q., S.W. Cui, Q. Wang and J.C. Young. 2008. Fractionation and physico chemical characterization of psyllium gum. Carbohyd. Polym., 73: 35-43.

Holzapfel, W.H., Haberer P., Geisen R., Bjorkroth, J. and Schillinger, U. 2001. Taxonomy and Important Features of Probiotic Microorganisms in Food and Nutrition. American J. Clin. Nutri., 73: 365-373.

IS: 12333. 1997. ISO 6731: 1989 Milk, Cream and Evaporated milk. Determination of total Solids Content. Manual for Analysis of Milk and Milk Products.

Ishibashi, N. and Shimanura, S. 1993. Bifidobacteria: research and development in Japan. J. Food Technol., 47: 126.

Jacobsen, C.N., Nielsen V.R., Hayford, A.E., Meller PL, Michaelsen, K.F., Pærregaard, A., Sandström, B., Tvede, M. and Jakobsen, M. 1999. Screening of probiotic activities of forty-seven strains of Lactobacillus sp. by in-vitro techniques and evaluation of colonization ability of five selected strains in human. Appl. Environ. Microbiol., 65: 4949-4956.

Janda, J.M and Abbott, S.L. 2007. Mini Review: 16S rRNA Gene Sequencing for Bacterial Identification in the Diagnostic Laboratory: Pluses, Perils, and Pitfalls. J. Clin. Microbiol., p. 2761-2764.

Joanne Slavin. 2013. Fiber and Prebiotics: Mechanisms and Health Benefits. $J$. Nutrients, 5(4): PMC 3705355.

Libudzisz, Z. and Stepaniak, L. 2003. Buttermilk. In: Encyclopedia of Dairy
Sciences, Vol 2, pp 1028-1034. Roginski H, ed. Oxford, UK:Academic Press.

Markiewicz, L. and Biedrzycka, E. 2005. Identification of Lactobacillus and Bifidobacterium species with PCR applied to quality control of fermented dairy beverages. Polish J. Food Nutrition and Sci., 14/55: 359-365.

Martin-Diana, A.B., Janer, C. and Requena. T. 2003. Development of a fermented goats milk containing probiotic bacteria.International Dairy J., 13: 827833.

Ouwehand, A.C., Salminen, S. and Isolauri, E. 2002. Probiotics: an overview of beneficial effects. Antonie van Leeuwenhoek, 82(1): 279-289

Sailaja Palthur, et al. 2014. Development and Evaluation of Cinnamon Flavored Buttermilk. Frontiers in Food \& Nutrition Res.

Saito, T. 2004. Selection of useful probiotic lactic acid bacteria from Lactobacillus acidophilus group and their application to functional foods. Animal Sci. J., 75(1): 1-13.

SAS. 1996. Statistical Analysis System for windows. In: SAS / STAT user'guide, version 4.10, release 6.12. SAS Institute Inc. Cary, NC. USA

Singh, R. and Jha, Y.K. 2005. Effect of sugar replacers on sensory attributes, biochemical changes and shelf-life of shrikhand. J. Food Sci. Technol., 42(5): 199-202.

Sodini, I., Morin, P., Olabi, A. and Jim_enezFlores, R. 2006. Compositional and functional properties of buttermilk: a comparison between sweet, sour, and whey buttermilk. J. Dairy Sci., 89: 525536.

Sonalika Srivastava, et al. 2015. Studies on Utilization of Buttermilk in Chapati Making. Int. J. Res. Emerg. Sci. Technol., volume-2, issue-10. 
Tamine, A.Y. and Robinson, K. 2004. Yoghurt Science and Technology, Published by Institute of Applied Science. Wood Head Publishing Limited, Cambridge England.

Tepper, B.J. and Trail, A.C. 1998. Taste or health: a study on consumer acceptance of corn chips. Food Quality and Preference, 9(4): 267-272.

Verbeke, W. 2006. Functional foods: consumer willingness to compromise on taste for health. Food Quality and Preference, 17(1): 126-131

Washington, N., M. Harris, A. Musselwhite, and R.C. Spiller. 1998. Moderation of lactulose-induced diarrhea by psyllium: effects on motility and fermentation. Am. J. Clin. Nutr., 67: 317-321.

Webb, B.H., A.H. Johnson, et al. 1974. Fundamentals of Dairy Chemistry. Westport, CT, The AVI Publishing Company, Inc.

\section{How to cite this article:}

Deepika Shree, K., H.W. Deshpande and Bhate, M.A. 2017. Studies on Exploration of Psyllium Husk as Prebiotic for the Preparation of Traditional Fermented Food "Buttermilk". Int.J.Curr.Microbiol.App.Sci. 6(7): 3850-3863. doi: https://doi.org/10.20546/ijcmas.2017.607.397 